\title{
FORMAÇÃO DE PROFESSORES NA PARAHYBA DO NORTE: INICIATIVAS PARA A SUA INSTITUCIONALIZAÇÃO (1861 a 1883)
}

\author{
Rose Mary de Souza Araújo ${ }^{1}$
}

\section{RESUMO}

O presente artigo trata de um estudo sobre o movimento e constituição histórica da formação de professores na Parahyba do Norte. Para tanto analisou-se as iniciativas de institucionalização da formação de professores ensaiadas no período de 1861 a 1883 . A análise dessas iniciativas assenta-se no materialismo histórico dialético a partir dos referenciais elaborados por Thompson (1981) e Gramsci (1989). O corpo documental é composto por: legislações, relatórios e mensagens de gestores públicos paraibanos e jornais locais. Constata-se que na realidade paraibana oitocentista as iniciativas para institucionalizar a formação de professores foram atravessadas por conflitos políticos adversos, não lograram êxito e foram projetadas sob os princípios iluministas difundidos pela modernidade.

Palavras-chave: Formação de professores; Escola Normal; Paraíba; Império

\section{TEACHER EDUCATION IN NORTH PARAHYBA: INITIATIVES FOR INSTITUTIONALIZATION (1861-1883)}

\begin{abstract}
This article deals with a study of the movement and historical constitution of teacher education in North Parahyba. Therefore we analyzed the initiatives institutionalization of teacher tested in the period from 1861 to 1883 . The analysis of these initiatives is based on the historical and dialectical materialism from the benchmarks developed by Thompson (1981) and Gramsci (1989). The body of documents is composed of: laws, reports and messages paraibanos public managers and local newspapers. It appears that in reality paraibana nineteenth initiatives to institutionalize the training of teachers were crossed by adverse political conflicts, were unsuccessful and were designed under the principles disseminated by Enlightenment modernity.
\end{abstract}

Keywords: Teacher education, Normal School, Paraíba, Empire

\section{Primeiras palavras}

A produção acadêmica acerca da história da formação docente e da escola normal no Brasil sugere que nas primeiras décadas do oitocentos, deram-se os primeiros passos para a sua institucionalização. Esse processo foi impulsionado pela crença na instrução popular como instrumento propulsor na construção da civilidade e do progresso social propugnados pelo ideário iluminista que contornou a modernidade. $\mathrm{Na}$ verdade, a demanda social por instrução e educação popular, impôs a formação de um quadro docente habilitados numa instituição específica - a Escola Normal - que por sua vez possibilitaria, dentre outros aspectos, solucionar os problemas recorrentes da instrução pública primária nas demais províncias brasileiras. 
Assim, este artigo trata de um estudo sobre o movimento e constituição histórica da formação de professores na Província da Parahyba do Norte - assim denominada até a instauração do regime republicano - no oitocentos. O objetivo principal é analisar as iniciativas de institucionalização da formação docente projetadas por gestores públicos no período de 1861 a 1883.

$\mathrm{Na}$ temporalidade acima, o contexto da província paraibana era caracterizada por um tensionado jogo de poder entre as lideranças políticas locais e pela difusão dos princípios propugnados pelo movimento iluminista francês. Ancorando-se nesses princípios, os gestores locais indicaram a formação de professores como condição necessária à expansão, à melhoria e modernização dos serviços educacionais referentes à instrução pública primária, por conseguinte, o progresso social da Província. Nessa perspectiva, foram encetadas algumas iniciativas e/ou tentativas de formar professores para as atividades instrucionais nas escolas primárias. Interessante registra que essas iniciativas, conforme discutidas a seguir, assumiram diversas configurações tais como: classes normais, aulas normais, cursos normais e finalmente escolas normais.

Finalmente o texto se apóia nos referenciais interpretativas de Thompson (1981) acerca do papel das evidências e dos fatos na compreensão do movimento histórico e de Gramsci (1989) no sentido de entender as forças sociais em jogo na Parahyba do Norte e suas respectivas intenções de promover a instrução primária e a formação dos professores. O corpo documental utilizado foram os discursos e relatórios elaborados pelos presidentes da província paraibana, os relatórios dos diretores da instrução pública dirigidos aos presidentes provinciais locais, as legislações acerca da instrução pública e da formação de professores que foram sancionadas no período em estudo e que se encontram na Coleção de Leis e Regulamentos da Instrução da Paraíba no Período Imperial e a produção jornalística de época. Embora o trabalho de investigação tenha privilegiado um contexto específico, buscou-se olhar sobre as fontes documentais a partir de um grande desafio metodológico: articular as particularidades com os dados mais gerais acerca da constituição da formação de professores, ancorando-se no pressuposto de que o conhecimento histórico é sobretudo provisório e limitado.

\section{Classes normaes: a regeneração do ensino}

Igualmente às outras províncias brasileiras a Parahyba do Norte, conforme com suas especificidades locais - base econômica algodoeira sob controle das oligarquias, clientelismo e a formação do poder de base familiar - também passou a ensejar mudanças no âmbito da educação escolarizada. Entre essas mudanças, estava pontuada a necessidade de implantar uma instituição que promovesse a formação de professores com vistas a equacionar os problemas na instrução pública, sob a crença da civilização e do progresso sócio-econômico da Província. Verificou-se que os primeiros sinais dessa necessidade através de escolas normais, surgiram já em 1837, três anos após a publicação do Ato Adidional, a partir do discurso do gestor provincial Bazilio Quaresma Torreão.

A partir de então, constata-se a predominância de vários discursos, reclamações e denúncias por partes dos gestores públicos acerca do despreparo e das práticas dos professores das escolas primárias paraibanas. Contudo, apenas em 1861 surgiu a primeira iniciativa de implantação de um ensino específico para a formação de professores. $\mathrm{O}$ argumento primordial para sua criação recaiu sobre a questão da regeneração e modernização do ensino público na Parahyba do Norte, conforme vinha sendo efetivado 
em outras províncias brasileiras e nos países europeus, principalmente na França, ao instituir a sua Escola Normal destinada à preparação de professores públicos.

A primeira necessidade é, pois, instituir a pedagogia - crear o professorado - acerca do que nada temos; nem escola normal, propriamente dita, nem escola modelo, conforme a pratica de alguns paizes da Europa, onde se concede essa cathegoria ás escolas mais bem regidas, e que melhores resultados dão, nem as classes normaes, systema usado a principio na Hollanda, e hoje até em algumas das nossas Proivincias, que consiste em dar aos alumnos das escolas communs, que mais aptidão e vocação manisfestão, lições especiaes sobre a pedagogia, e principalmente em empregal-os nos exercicios das classes, a principio como alumnos mestres, e depois como adjuntos, até que passão á professores effectivos, etc. (PARAHYBA DO NORTE, Relatório, 1861, p. 2, grifos nossos).

Assim, o diretor da Instrução Pública Diogo Velho Cavalcanti de Albuquerque propôs a criação das Classes Normaes destinadas apenas ao sexo masculino, dentro das dependências do Liceu Provincial, em virtude da situação financeira da Província. Essas classes, conforme determinava o mencionado Diretor, tinham como finalidade preparar os professores primários, de que a instrução pública tanto necessitava. O imperativo categórico era o de regenerar com urgência o ensino primário da Parahyba do Norte. Todavia, com exceção do programa de ensino prescrito para formar aqueles professores, não estabeleceu a sua organização, principalmente no que se referia a questão do tempo de duração do curso e quais professores iriam lecionar nas "classes normaes".

Os saberes estabelecidos para a formação docente eram os mesmos que estavam organizados para o ensino primário em nível de $2^{\circ}$ grau. Observa-se que as denominadas "lições especiais sobre pedagogia", ou seja, possivelmente os saberes relacionados diretamente com a formação pedagógica para o exercício do magistério, ficaram ausentes. Interessa observar que esta ausência negou parte da finalidade do foi proposto, sugerindo, portanto, que aos futuros professores cabiam necessariamente dominar os conhecimentos que deveriam ser transmitidos nas escolas primárias. Assim sendo, as "classes normaes" com vistas a preparar professores para a regeneração do ensino primário paraibano, tinham como suporte de formação o conjunto de saberes disposto no quadro 1.

Com efeito, é possível verificar que a tendência de formação de professores nas classes normaes tinha três eixos: o primeiro de caráter utilitário caracterizado pelas seguintes disciplinas: Sistema legal de pesos e medidas da província, Princípios gerais de economia política, Escrituração e contabilidade mercantil e Noções gerais de economia rural; o segundo, de cultura geral, expresso nas disciplinas: Leitura e escrita, Elementos da língua nacional, Elementos práticos de cálculo até as regras de companhia, Noções gerais de geometria prática sem demonstrações e Noções elementares de geografia e história pátria. Enquanto o último eixo de caráter moralizante representado pelas disciplinas Instrução religiosa e Instrução moral. 
Quadro 01

Programa de ensino nas classes normaes

\begin{tabular}{|l|}
\hline 1. Instrução religiosa \\
\hline 2. Instrução moral \\
\hline 3. Leitura e escrita \\
\hline 4. Elementos da língua nacional \\
\hline 5. Elementos práticos de cálculo até as regras de companhia \\
\hline 6. Noções gerais de geometria prática sem demonstrações \\
\hline 7. Sistema legal de pesos e medidas da província \\
\hline 8. Noções elementares de geografia e história pátria \\
\hline 9. Princípios gerais de economia política \\
\hline 10. Escrituração e contabilidade mercantil \\
\hline 11. Noções gerais de economia rural \\
Fonte: Quadro organizado pela autora a partir dos dados contidos na \\
$\quad$ documentação: Parahyba do Norte, Relatório, 1861, p. 6.
\end{tabular}

A dimensão formativa expressa nos eixos destacados acima mantém similitude com as considerações de Gramsci em torno da escola e dos seus programas de ensino. Esses, na perspectiva do autor citado geralmente revelam o tipo de escola organizada dentro de um determinado ambiente social político, ou seja, a escola e os seus programas de ensino não passam de uma trama sócio-política. Portanto, "A marca social é dada pelo fato de que cada grupo tem um tipo de escola próprio, destinado a perpetuar nestes grupos uma determinada função tradicional, diretiva ou instrumental". (GRAMSCI, 1988, p. 136).

A proposta de instituir "classes normaes" tornou-se um discurso estéril, pois no ano seguinte, o seu idealizador, ainda na condição de Diretor da Instrução Pública, elaborou um outro relatório bastante detalhado sobre a situação do ensino público. Nesse lamentou que as medidas práticas que propôs para a reorganização do mesmo, não foram levadas em considerações pelas autoridades competentes, inclusive a proposta de criação da Escola Normal, além daquelas classes. Enfatizou ainda que este fato concorreu para a ampliação do estado "desolador" e de abandono do ensino primário público. Em função da situação apresentada em seu Relatório, insistiu na criação de uma Escola Normal aproveitando a estrutura do Liceu Provincial. No referido documento enviado ao presidente da Província Francisco d'Araujo Lima em 1862, elaborou as seguintes considerações, que no seu entendimento contribuiria efetivamente para a "reorganização radical na instrução":

A desfavoravel situação financeira da Provincia tem sido o motivo allegado para justitficar a pouca attenção prestada a assumpto tão momentoso por aquelles, que por suas luzes e posição podião auxilial-o com as providências mais urgentemente reclamadas.

Entendo que meia duzia de contos de réis applicados a instrucção das classes normaes em algumas de nossas escolas mais acreditadas, ao fornecimento dos utensilios e moveis indispensaveis ao regimen escolar, e ao preparo material das aulas, de modo que ellas podessem funccionar com mais decencia e regularidade, nem desfalcaria o nosso budgt, nem seria uma despeza inutil, como talvez a muitos pareça, mas um capital posto a juros, que renderia grossa somma de lucros moraes. (PARAHYBA DO NORTE, Anexo G, p. 1-2).

Ressalta-se que em seu último relato, frisou que as justificativas para o não atendimento das medidas educacionais necessárias, sempre recaíram na precária situação 
financeira da Província, contudo, sustentou a falta de vontade política dos gestores locais no trato da educação popular. Assim se expressou:

As dificuldades financeiras são sempre a causa trazida como justificativa de tão completo abandono; e a não haver vontade enérgica de alguem que, tendo competencia para faze-lo, quizer applicar uma parte, embora pequenas, das rendas da Provincia ao objecto de que me occupo, nunca, nem mesmo na Capital haverá uma casa de escola. (PARAHYBA DO NORTE, Anexo G, 1862, p. 3, grifos nossos).

É oportuno considerar que a conjuntura de então apresentava diversos elementos conflitantes. De um lado, a situação econômica da Parahyba do Norte vinha ganhando força em função da valorização da cultura algodoeira. Do outro, registrava-se uma grande pobreza, além de um panorama severamente marcado por epidemias de febre amarela, sarampo, cólera-morbus e de varíola, que fizeram muitas vitimas (MELO, 1994, p. 112113).

Como expressão de síntese, as evidências revelam que a tentativa de implantação das classes Normaes idealizadas por Diogo Velho Cavalcanti de Albuquerque, não chamou atenção das lideranças políticas de então. Portanto, mesmo de forma acanhada, uma oportunidade de formar professores foi perdida em face dos interesses políticos que caracterizava aquele momento.

Todavia, persistiram os discursos e reclamações tanto dos gestores da instrução pública quanto dos presidentes da Província sobre a situação de precariedade da instrução pública. Ao diagnosticar sobre a realidade da mesma, era comum pontuar, como causa primordial a falta de um quadro de professores habilitados. Não obstante a defesa pela Escola Normal, poucos apresentaram projetos para a implantação de uma escola normal. $\mathrm{Na}$ sua maioria, sugeriam mecanismos que não passavam de improvisação de preparação de professores. Anos mais tarde, surgiu uma nova tentativa legalizada através da Lei $\mathrm{N}^{\mathrm{o}}$. 178 de 30 de novembro de 1864 , analisada a seguir.

\section{Escola Normal: instrução e moralidade}

Em 1864, o presidente Sinval Odorico de Moura, em seu discurso na Assembléia Legislativa paraibana observou que a legislação da Instrução Pública vigente, o Regulamento de 11 de Março de 1852, se apresentava "defeituosa e cheia de lacunas". Realçou ainda que os professores em exercícios não tinham habilitação adequada para as atividades instrucionais primárias. Baseando-se nesta constatação, enfatizou a necessidade de uma reforma radical para impulsionar o desenvolvimento e modernização dos serviços educacionais de que a Província necessitava para o seu progresso sócio-econômico.

Sob a influência dos herdeiros da ilustração francesa, observa-se nos seus argumentos, a crença na instrução pública como instrumento primordial na construção da civilidade e progresso social. Nessa empreitada, não deixou de destacar a importância de formar professores com habilidades necessárias para o exercício do magistério primário, ao mesmo tempo a sua concepção acerca da prática docente, a saber: santo sacerdócio. Não obstante até aquela data, nenhum projeto foi apresentado e regulamentado no que se referiu à formação específica do professor. Para ratificar o exposto, destaca-se um trecho do discurso do mencionado presidente. 
Para ter bons discípulos é preciso ter bons mestres, e estes não se podem improvisar de um para outro momento, visto como não ha sacerdocio mais carecedor de um grave noviciado, do que o santo sacerdocio do educador. (PARAHYBA DO NORTE, Relatório, 1864, p. 7, grifo nossos).

Pode-se verificar que os interesses das lideranças locais não estavam voltados para uma educação popular. A necessidade era a de consolidar as suas bases de poder tanto político quanto econômico. Destarte, a força do patronato e do clientelismo político se fez atuante também naquele setor, desviando assim, o debate sobre a expansão da instrução popular e da formação do professor através de uma escola normal.

Incomodado com a referida situação, o Diretor da Instrução Pública, João Florentino Meira de Vasconcelos, membro efetivo do grupo liberal, em seu Relatório de 1864, denunciou a interferência do patronato político, da facção do grupo conservador local, especificamente na escolha do quadro de docente para o ensino primário público. Considerando o conteúdo impresso nas denúncias e críticas apresentadas no referido documento, é possível afirmar que o trânsito do patronato no setor educacional contribuiu também para a descaracterização do exercício do magistério, refletindo, portanto, o favorecimento pessoal por aqueles que detinham o poder econômico e político, tendo em vista a manutenção e extensão desses. Esse protecionismo político, enquanto termômetro de habilitação e da escolha do pessoal para o magistério público, foi revelado da seguinte forma:
A empregomania é defeito, senão vicio de nossos homens: quem não dispõe de recursos para a vida commercial, ou não possue escravos para arrotear a terra, entende somente dever viver á custa dos cofres públicos, engano em que vivem os habitantes de um paiz fertil e productivo, como o nosso. E assim aquelle, que não tem um meio de vida, olha para uma cadeira de $1{ }^{\text {as }}$ lettras, como recurso mais prompto; e conforme a proteção de que dispõe, vai sendo preferido a outro, embora mais habilitado, e de melhor conducta, porem menos protegida!!! (PARAHYBA DO NORTE, Relatório, 1864, p. 35).

Igualmente ao seu antecessor, chamou atenção para situação em que se encontrava a instrução primária pública, onde a causa dos seus problemas, além da ingerência do patronato político local, estava na falta de professores habilitados e com formação moral adequada para as atividades instrucionais. Nesse sentido defendeu a premissa de que professores com formação pedagógica e moral concorreriam para a promoção da qualidade do ensino na Parahyba do Norte. Assim, vislumbrando a melhoria da qualidade daquele ensino enfatizou como medida indispensável a criação de uma ou mais escolas normais que proporcionasse a referida formação dentro de um período mais longo através de atividades teóricas e práticas relacionadas ao exercício do magistério.

Contrapondo-se a prática do concurso e objetivando tanto o reconhecimento social do magistério quanto à melhoria da qualidade da instrução pública na província paraibana elaborou uma proposta de criação da Escola Normal. Essa instituição, para o Diretor supra citado, tinha como finalidade primordial formar o bom professor para realizar satisfatoriamente as atividades de ensino voltadas para a mocidade paraibana. $\mathrm{O}$ bom professor, necessariamente, além de um vasto conhecimento intelectual, deveria atender as seguintes exigências: "vocação, amor à profissão, e boa conducta civil e moral". (PARAHYBA DO NORTE, Relatório, 1864, p. 40). A partir desses parâmetros, provavelmente considerando que a maioria dos professores com exercício nas escolas 
públicas era do sexo masculino, sugeriu a criação de escolas normais destinadas apenas para esse sexo sob a modalidade de funcionamento em graus, como mecanismo que poderia proporcionar tanto o aperfeiçoamento dos professores, quanto uma forma de estímulo à carreira docente.

Uma ou mais escolas normaes confiadas a professores distinctos, onde pela pratica e exercicio de annos adquirirão habilitação aquelles, que quizerem se dedicar ao magistério.

Por essa forma não só ficarão reconhecidas e provadas as habilitações intellectuaes, como também a vocação, gosto, amor, dedicação $e$ conducta do moço a quem deve ser confiada a gerencia de uma cadeira publica: e uma vez que haja boa vontade, sinceridade e justiça na escolha, há de ser sempre acertada a nomeação, e havemos de ter bons professores. (PARAHYBA DO NORTE, Relatório, 1864, p. 42, grifos nossos).

No mês seguinte da publicação do mencionado documento, entende-se que surgiu a segunda tentativa de formar professores, agora na Escola Normal oficializada através da Lei $\mathrm{N}^{\circ} .178$ de 30 de novembro de 1864 que havia organizado a instrução tanto primária quanto a secundária. Apesar do esforço, a citada lei se apresentou lacunosa, ou seja, faltou um maior detalhamento acerca da organização e do funcionamento daquela instituição que teoricamente, deveria concorrer para a melhoria da qualidade da instrução pública, em específico, o ensino primário na província paraibana. Ressalta-se ainda que não foi encontrado nenhum registro e/ou vestígio que indicasse a existência do regulamento sugerido no parágrafo quinto do artigo abaixo que tratou da criação da Escola Normal.

Quanto aos saberes - quadro 02 - que dariam suporte a formação dos futuros professores, eram os mesmos estabelecidos no programa do denominado ensino superior, conforme foi determinado no terceiro parágrafo do artigo primeiro da Lei № ${ }^{\circ} 178$ de 1864 . Dessa forma, ficou evidenciado que caberiam aos futuros professores, em seu processo de formação, dominar os conteúdos que deveriam posteriormente ser ensinados nas referidas escolas.

\section{CAPÍTULO $3^{\circ}$}

Escola Normal

Art. $8^{\circ}$ - Será criada uma escola normal, onde se habilitem os candidatas ${ }^{2}$ ao magistério.

$\S 1^{\circ}-\mathrm{O}$ professor da escola normal terá mais cem mil réis de ordenado do que as do ensino superior, e somente será vitalício depois de 5 anos de efetivo exercício.

$\S 2^{\circ}-\mathrm{O}$ provimento desse professor também terá lugar em virtude de concurso, podendo ser nomeado interinamente na falta de concorrentes.

$\S 3^{\circ}$ - Se no espaço de 4 anos essa escola não tiver frequiência suficiente, e nem oferecer utilidade, será suprimida.

$\S 4^{\circ}-\mathrm{O}$ ensino da Escola Normal compreenderá as matérias do ensino superior e mais aquelas que o Presidente designar, ouvindo o Diretor.

$\S 5^{\circ}-$ No respectivo Regulamento será determinado curso, e tempo de estudos, exames e mais condições de habitação nessa escola. (Apud PINHEIRO; CURY, 2004, p. 44). 
Quadro 02

Programa de ensino da Escola Normal - Lei 178 de 30/11/1864

\begin{tabular}{|l|}
\hline 1. Leitura e escrita \\
\hline 2. Noções de gramática \\
\hline 3. Doutrina cristã \\
\hline 4. Aritmética até suas operações por números inteiros, \\
\hline 5. Noções de gramática prática \\
\hline $\begin{array}{l}\text { 6. Aritmética em suas operações em decimais quadrados e em complexas e } \\
\text { proporções }\end{array}$ \\
\hline 7. Gramática da língua nacional \\
\hline 8. Noções elementares da história sagrada \\
\hline 9. Sistema de pesos e medidas \\
\hline 10. Elementos de geometria \\
\hline 11. Noções do evangelho \\
\hline 12. Noções da Geografia \\
\hline 13. História do Brasil \\
Fonte: Quadro organizado pela autora a partir dos dados contidos na obra: Pinheiro; \\
Cury, (2004, p. 42).
\end{tabular}

É possível notar que o conjunto dos saberes propostos naquela Lei, se esgotava na cultura geral e nos princípios doutrinários da moral cristã, que, após ser assimilados e dominados pelos futuros professores, deveriam ser transmitidos aos alunos tanto nas escolas de $1^{\circ}$ grau, quanto de $2^{\circ}$ grau em dosagem diferenciada. Com feito, estavam em vias de consolidação as orientações das lideranças políticas da época: controle e conformação social. Em verdade, ficaram explícitos dois eixos básicos que versariam a formação de professores proposta naquele dispositivo. O primeiro eixo denominou-se de cultural caracterizado pelas seguintes disciplinas: leitura e escrita, noções de gramática, aritmética até suas operações por números inteiros, noções de gramática prática, aritmética em suas operações em decimais quadrados e em complexas e proporções, gramática da língua nacional, sistema de pesos e medidas, elementos de geometria, noções da geografia e história do Brasil. Quanto ao segundo eixo classificou-se de moralidade, em virtude das seguintes disciplinas: doutrina cristã, noções elementares da história sagrada e noções do evangelho3. Assim sendo, entende-se que as dimensões da cultura e da moralidade formavam o núcleo constitutivo da Escola Normal que foi estabelecida na Lei $N^{\circ} .178$ de 1864.

Na documentação disponibilizada até o momento final da investigação nos arquivos sediados em João Pessoa, não se encontrou nenhuma pista que pudesse indicar o funcionamento daquela instituição. Todavia considerando os debates que sucederam a oficialização da Escola Normal de 1864, cogita-se que não foi efetivada em termos da prática.

Para encerrar esta seção, opta-se por colocar em evidência alguns trechos de relatórios e mensagens de gestores públicos por revelarem dois aspectos importantes para a reconstrução histórica da formação de professores na Província da Parahyba do Norte no oitocentista. O primeiro refere-se a confirmação da tese de que a Escola Normal estabelecida legalmente em 30 de novembro de 1864, não foi efetivada de fato. O outro aspecto revelado está relacionado com a ideia recorrente de que na Escola Normal era creditada a esperança de uma melhoria na instrução pública paraibana. A referida crença estava pautada no pensamento de que essa instituição poderia qualificar e formar pedagogicamente os professores para as atividades nas escolas primárias. Assim, constatase que o discurso da época incorporou a base vocacional, sacerdotal no processo de formação de professores para a base pedagógica, profissional propriamente dita. Os discursos abaixo ratificam o exposto. 
Chamo primeiramente a judiciosa attenção de V. Exc. Para o art. $8 .^{\circ}$ da Lei $\mathrm{N}^{\circ} 178$ de 30 de novembro de 1864, que manda crear na Capital uma aula de ensino normal. A instauração desta é de urgente e primeira necessidade nas circumstancias actuaes, em que se precisa de um pessoal instruído [...]. (PARAHYBA DO NORTE, Anexo N.8, 1866, p.10).

Para isso julgo de utilidade a instituição de uma escola normal á similhança das que teem sido creadas em outras provincias, na qual aquelles que se votam ao magisterio aprendam theorica e praticamente as boas regras da Pedagogia, e conheçam o modo e a opportunidade da applicação d'ellas. (PARAHYBA DO NORTE, Falla, 1873, p. 20).

Não ha professorado escolhido sem ser preparado d'ante-mão por escolas para isso destinadas, sem uma instrucção technica: não ha bons discipulos, sem bons professores. (PARAHYBA DO NORTE, Relatório, 1879 , p. 28).

Aquele pensamento e/ou ideário que sustentavam o movimento em torno da implantação de uma Escola Normal destacado acima, impulsionou outras tentativas projetadas, ensaiadas e legalizadas para formar professores para as escolas primárias. A seguir analisa-se a Escola Normal enquanto curso e/ou aula no Liceu Provincial Paraibano.

\section{Curso Normal e Cadeira de ensino normal no Liceu Provincial}

Sob alegação da falta de recursos públicos4 para solucionar os diversos problemas que atravessavam a instrução pública e para a instalação de uma escola normal que já vinha sendo proclamada, em 1867 o Barão de Maraú sugeriu a criação de uma cadeira de língua nacional no Liceu Provincial. Essa tinha como meta fundamental prevista, preparar professores públicos para minimizar os problemas instrucionais em nível primário. Assim, surgiu uma proposta de improvisação para formar professores "qualificados" dentro de um prazo ínfimo que variava de três a seis meses.

Uma proposta um tanto evasiva e empobrecida para qualificar um quadro de professores habilitados, uma vez que os discursos dos gestores de época estavam ancorados nos pressupostos iluministas. Registra-se que não foi encontrado nenhum registro que nos mostrasse quais matérias teóricas e práticas deveriam subsidiar a formação de professores dentro de uma cadeira denominada de língua nacional naquele interstício. Destaca-se a seguir algumas de suas considerações, ou talvez apelos:

Considero com effeito muito acertado a medida, porém, me parece melhor crear-se no Lyceu uma cadeira de língua nacional, a qual se reúna as matérias theoricas e praticas do professorado de instrucção primaria, onde serão obrigados os pretendentes a se habilitar por tres a seis mezes, obtendo do respectivo preceptor attestado de frequência, e aproveitamento, que, confirmado pela directoria, lhes sirva de documento para ser admittidos á concurso. (PARAHYBA DO NORTE, Relatório, 1867, p. 20).

Em seu Relatório de 1871, o diretor da Instrução Pública, Joaquim Moreira Lima retomou o debate acerca da implantação de uma escola normal. Para tanto, ressaltou que na Parahyba do Norte existia uma estrutura física pronta, com professores capacitados intelectualmente - o Liceu Provincial - que não vinha prestando serviços satisfatórios à comunidade, apenas onerando as finanças da província. Mediante essa constatação, propôs 
a criação de um Curso Normal no Liceu. Ora, uma alternativa parcimoniosa, pois, além do espaço físico, contava também com um pessoal habilitado e um programa de ensino já estabelecido que proporcionaria o preparo dos futuros professores. Observa-se nas suas palavras a seguir, como idealizou a criação daquele curso.

Reconheço a dificuldade: porém parece-me que poderá ser resolvida á contento, uma vez que o curso normal faça parte integrante do lycêu desta capital e sejam encarregados de seus trabalhos didaticos os lentes actuaes, cujas cadeiras não tem frequencia.

Possúe o Licêu professores habilitadissimos, a maioria dos quaes permance há annos em completa e lamentavel inactividade: porque, pois, não aproveitarem-se os seus conhecimentos na instrucção dos que pretendem ao magistério do ensino primário? [...]. (PARAHYBA DO NORTE, Relatório, 1871, p. 7).

Considera-se que essa tentativa de formar professores e ao mesmo tempo de organização da Escola Normal paraibana, fundamentando-se nas análises de Kulesza (2000) e de Lopes (2008), de certo modo mantinha similitude com o modelo implantado, mesmo com o tempo de serviço efêmero, em outras províncias brasileiras. Provavelmente era uma alternativa que os poderes constituídos locais encontraram para não onerar os cofres públicos, vez que as orientações estabelecidas foram: a) utilização das dependências físicas e b) aproveitamento do corpo docente dos liceus provinciais.

Ressalta-se ainda que no mesmo período, impulsionado pela conjuntura de então, conforme Almeida (2000, p. 128), o conselheiro ministerial João Alfredo Correia de Oliveira em 1872, sugeriu várias medidas educacionais a serem implantadas na Corte Imperial. Dentre elas, a criação de escolas normais em caráter urgentíssimo.

Algumas medidas me aparecem urgentes: a criação imediata de duas escolas normais, uma para alunos-mestres, uma para alunas-mestras. $\mathrm{O}$ programa dos estudos e a lista dos livros a adotar nestas escolas serão preparados pelos respectivos diretores, ajudados pelos professores submetidos à aprovação do governo.

No embate político e ideológico entre conservadores e liberais, que caracterizava a conjuntura tanto em nível nacional quanto local, Silvino Elvidio Carneiro da Cunha Barão de Abiahy - na ocasião estava na posição de líder do grupo conservador local (MELO, 1994, p. 123), não deixou de tomar parte em defesa da institucionalização da Escola Normal da Parahyba do Norte. Na condição de gestor provincial, ainda fundamentando-se nos pressupostos iluministas, sem apresentar uma proposta de funcionamento, enfatizou a necessidade de estabelecer o ensino primário obrigatório como também a institucionalização de uma escola normal.

Portanto, em seu Relatório datado do ano de 1874, colocou em pauta a importância de qualificar adequadamente o professor conforme a condição de sexo, como elemento indispensável para dar novos rumos ao ensino primário, ou seja, "offerecer garantia de progressivo desenvolvimento". (p. 26). Nessa perspectiva, realçou que era "necessária uma escola normal para cada um dos sexos onde sejam preparados os que se destinam ao professorado".

No mesmo ano foi criada uma cadeira de ensino normal através da Lei $\mathrm{N}^{\circ} .564$ de 28 de setembro. A referida cadeira tinha como finalidade formar professores apenas do sexo masculino para exercer as atividades escolares inerentes ao ensino primário. $\mathrm{O}$ seu funcionamento estava previsto para acontecer nas dependências do Liceu Paraibano. 
Assim, foi projetada a terceira tentativa de se normatizar a formação de professores. A mencionada lei elaborou as seguintes recomendações:

Art. $1^{\circ}$ - Fica criada no Liceu desta capital uma cadeira de ensino normal, tendo o professor os mesmos vencimentos dos atuais lentes daquele estabelecimento.

Art. $2^{\circ}$ - Esta cadeira será destinada a preparar os candidatos ao professorado da instrução primária do sexo masculino, as quais, sem aprovação plena nos respectivos exames, não poderão apresentar-se em concurso.

Art. $3^{\circ}$ - As matérias da referida cadeira serão de escolha da congregação dos lentes do Liceu com aprovação do Presidente da Província, para sua execução, regulando-se depois do mesmo modo, por que são determinadas anualmente no dito estabelecimento.

Art. $4^{\circ}-\mathrm{O}$ primeiro provimento desta cadeira, bem como da de língua nacional, será de nomeação do Presidente da Província, independente de concurso, afim de que possa imediatamente funcionar, observando-se nos demais provimentos o regulamento de 11 de março de 1852. (apud PINHEIRO; CURY, 2004, p. 131-132).

As raríssimas informações disponibilizadas indicaram que aquela cadeira de ensino normal não passou de uma malograda improvisação de formação de professores. Funcionou apenas com um professor do Liceu Paraibano, Joaquim Inácio de Lima Moura, que lecionava todas as disciplinas apenas para oito alunos do sexo masculino efetivamente matriculados (MELLO, 1956, p. 52). Quase dois anos depois, o artigo terceiro da Lei de No. 633 de 26 de julho de 1876 (PINHEIRO; CURY, 2004, p. 132), extinguiu aquela cadeira de ensino normal. Apesar de simplória, entende-se que mais uma oportunidade de formar professores para a instrução primária, fracassou, ou quem sabe, ainda não tinha recebido o devido valor pelas lideranças locais.

O presidente provincial que sancionou a sua extinção, ou seja, deu o golpe naquela possibilidade inicial de preparar professores, o então Barão de Mamanguape, em 1876, fez alusão àquela cadeira enquanto instituição que não respondia satisfatoriamente a finalidade a que se propôs, expressando-se da seguinte forma: "[...] nossa Escola Normal, organisada como se acha, não satisfaz ao fim da sua instituição". (p. 14). Considerou também inoperante o processo de formação de professores ministrado por um único professor. Os argumentos abaixo justificaram a sua extinção:

Criada pela Lei 564 de 28 de setembro de 1874, funcciona a Escola Normal no Lyceu da Capital, sendo actualmente frequentada por 8 estudantes. As Materias, que ahi se professam, forão designadas pela Congregação dos Lentes do Lyceu; e comquanto fosse limitado o numero d'ellas, é, todavia, impossível que sejam ensinadas por um só Professor. (PARAHYBA DO NORTE, Relatório, 1876, p. 14, grifo nosso).

Todavia registrar-se que o gestor provincial, Esmerino Gomes Parente, em seu Relatório de 1877 , não perdeu de vista o ideário da modernidade ora predominante na época - iluminista - tampouco, o hábito de tomar como referência outros países mais avançados culturalmente, para pensar e argumentar os problemas da instrução pública e em específico a formação de professores.

Em todos os paizes, e em todos os governos, a instrução popular é uma necessidade vital: todos os povos cultos do mundo a proclamão, como a 
solução do grande problema da regeneração social, e conhecem que na diffusão do ensino está o segredo de sua grandeza e de sua força. (p. 24).

Assim, não muito diferente de alguns de seus antecessores, enfatizou que a prosperidade e regeneração social somente poderiam ser concretizadas através da difusão do ensino primário de qualidade. E, para sua efetivação de fato, era necessário profissional, mestres com "vocação" específica para o magistério e devidamente qualificados numa escola normal, ou seja, no seu entendimento, qualquer investimento na instrução pública

[...] será completamente nulla, si não houver bons mestres, que tenham instrucção sólida, conhecimentos práticos, e vocação decidida para o magistério, e tenho por certo que estas habilitações não se encontram nos nossos professores, que mal preparados nas materias que constituem o ensino official recebem de presente a cadeira, á cujo concurso se opposeram, sendo este o maior mal, de que se resente a nossa instrução. (PARAHYBA DO NORTE, Relatório, 1877, p. 26).

Da mensagem acima, pode-se inferir que a preparação pedagógica por si só não era condição suficiente e necessária para promover em níveis melhores a instrução pública. Além de outros aspectos constitutivos já vistos antes, como a moralidade e o retorno da vocação. Portanto, pode-se presumir que teoricamente o processo de formação de professor para promover a instrução pública estava ancorado em três elementos básicos: saberes específicos de cultura geral, moralidade e vocação, apesar de que já vinha sendo difundida no meio educacional a necessidade da racionalidade técnico-científica no processo de formação docente.

Nesse período, a situação financeira da Parahyba do Norte estava fragilizada em virtude da grande seca que se estendeu por três anos, ou seja, de 1877 a 1879, devastando, principalmente a produção algodoeira, marco da economia da província (LEWIN, 1993, 56). Esse fenômeno natural associado aos efeitos do final da Guerra de Secessão, segundo Gurjão (1994, p. 25) alterou significativamente o quadro econômico-financeiro da Parahyba do Norte, agravando mais ainda a condição de miséria da população pobre. Nesse interstício, a preocupação dos gestores provinciais paraibanos era a de buscar soluções para os efeitos nefastos provocados pela referida seca, principalmente as epidemias e a fome que consternaram quase toda a população inserida da zona rural.

Todavia, a criação da Escola Normal, foi adiada e outros investimentos e até mesmo a manutenção dos serviços educacionais existentes foram severamente abalados, e muitas das vezes suprimidos. Na verdade, nenhuma medida de envergadura relacionada à instrução pública e à formação de docentes, puderam ser efetivadas tanto naquele momento quanto nos primeiros anos posteriores. Dessa forma, contribuiu para a ampliação das imperfeições e anacronismos estruturais e pedagógicas na instrução pública. Segundo Mello (1956, p. 53), essa "quasi que desapareceu, uma vez que o professorado, sem receber vencimentos, por anos seguidos, viu-se na contingência de abandonar as escolas, para procurar, noutro meio de vida, sua própria manutenção".

Mesmo com os entraves econômicos que vinham atravessando toda a vida social paraibana, resultante daquela seca, não suscitou desânimo naqueles que acreditavam na formação de professores numa escola normal. Para reiterar, o presidente da província, Manuel Ventura de Barros Leite Sampaio, mesmo considerando o precário quadro financeiro sugeriu uma alternativa provisória para preparar professores para e escola primária. 


\begin{abstract}
N'esta provincia quasi tudo está por fazer. Lutando há muitos annos com orçamentos diminutos, apenas sahida de uma tremenda crise que abaloulhe profundamente o credito, onerada de uma grande divida, a Parahyba ainda não pôde volver as suas vistas com affinco para este ponto.

Com quanto ainda não tenhamos uma eschola normal onde de habilitem os candidatos ao magisterio, necessidade de primeira ordem, todavia certas materias podem ser aprendidas do Lycêo e particularmente, taes como grammatica philosophia, arithmetica, princípios de geometria, geographia e historia sagrada e do Brazil, que são indispensaveis para um professor. (PARAHYBA DO NORTE, Relatório, 1882, p. 24).
\end{abstract}

Em suma, a tentativa de formar professores através de uma cadeira de ensino normal instalada no Lyceu Provincial, como visto não logrou sucesso. Não obstante, observando a mensagem do gestor acima mencionado, a importância de se ter professores qualificados era tão imperativa, que a idéia de fazer o uso das instalações da referida instituição não foi esquecida, haja vista as condições financeiras da província e o abandono em que se encontrava esta instituição educativa.

\title{
Conversão do Liceu Provincial paraibano em Escola Normal
}

A produção historiográfica e os documentos específicos à realidade paraibana, sugerem que após a publicação da Reforma Leôncio de Carvalho em 1879, o reconhecimento e importância sócio-educacional tanto da formação do professor através de uma escola normal, quanto do exercício do magistério, começaram a ser vistos como possibilidades reais. Na verdade, passaram a ganhar novos contornos, bem como reforçados enquanto condições e exigências imprescindíveis para o tão desejado progresso e modernização da Província.

Toda a euforia em torno da criação da escola normal estava alicerçada no artigo oitavo da referida reforma ${ }^{5}$, que, dentre outras, determinava que o Governo Central poderia criar ou auxiliar as demais províncias brasileiras a instituírem suas escolas normais. Efetivamente, a Parahyba do Norte, com base naquele dispositivo legal, não dispensou a possibilidade de finalmente ter a sua escola normal.

Possivelmente o governo monárquico pressionado, de um lado pelas lideranças políticas do grupo liberal e das demais províncias e do outro, pelos intelectuais envolvidos com a questão educacional, foi levado a cumprir com o parágrafo quinto do mencionado artigo, que mesmo imbuído do caráter condicional, determinava a sua responsabilidade com a criação e manutenção das escolas normais nas demais províncias do Império. Vejase como foi preconizado.

$\S 5^{\circ}$ Crear ou auxiliar Escolas Normaes nas províncias;

Art. $12^{\circ}$ Nas províncias o Governo só poderá abrir mesas de exames de preparatórios nas cidades onde, não existindo ainda estabelecimento em condições de obter a prerogativa do art. 8. ${ }^{\circ}$ n. 7, houver alguma Escola Normal organizada de conformidade com as disposições do art. 9. . (Actos do Poder Executivo - Decreto N. 7247 - de 19 de abril de 1879, p. 199).

Conforme matéria do Jornal da Parahyba de 25 de março de 1882, no dia 26 de novembro do ano anterior, havia chegado às províncias brasileiras, inclusive na Parahyba do Norte, um documento, reproduzido abaixo, intitulado de "aviso", proveniente do 
Ministério do Império, ordenando-as a fundarem suas escolas normais. Existem evidências que foi a partir desse documento, possivelmente forjado pela Reforma Leôncio de Carvalho, que a corrida pela implantação de escolas normais tomou um fôlego maior.

Ilm. E Exm. Sr. - Sendo uma verdade reconhecida que só por meio de escolas-normaes se pode conseguir um pessoal com precisa idoneidade para desempenhar as importantes funcções do magisterio, motivo pelo qual todas as nações cultas teem procurado multiplicar e desenvolver os estabelecimentos d'este genero, convém que V. Exc. Promova n'essa província, se á isso se não oppuzerem circumstancias especiaes, e segundo as respectivas condições financiais, a creação de uma escolanormal, que, á bem da unidade da organização do ensino em todo o imperio, deverá cingir-se quanto possivel ao plano estabelecido no art. 9. do decreto n. 7247 de 19 de abril de 1879.

Empenhado em vêr dotadas com uma instituição de tão subido alcance as provincias que ainda não gosam dos seus benefícios, o governo, de accordo com o pensamento manifestado no art. $8 .^{\circ} \S 5^{\circ}$ do citado decreto, prestará o indispensavel auxilio áquellas, que com os seus proprios recursos a não puderem fundar, se para este fim lhe forem concedidos pelo poder legislativo os meios necessarios, que solicitará.

A alludida creação assegurará á essa provincia as vantagens das mesas de exames gerais de preparatórios, visto que quando o governo julgar opportuno dar execução ao art. $12^{\circ}$ do referido decreto, só poderão gosar de taes vantagens aquellas em que, não existindo ainda estabelecimentos em condições de obter a prerogativa do art. $8 .^{\circ}$ n. 7. do mesmo decreto, houver alguma escola-normal organizada de conformidade com as disposições do mencionado art. 9. ${ }^{\circ}$.

Do zelo de V. Exc. Confia o governo que envidará os seus esforços no sentido indicado. ${ }^{6}$

É interessante relembrar que o contexto da época estava crivado por uma acirrada disputa política entre os grupos de então: conservador e liberal, ou seja, uma conjuntura onde a correlação de forças estava bastante exacerbada. Esse último, como já se referiu, estava ganhando credibilidade com seus ideais e pensamentos no espaço político da província em detrimento do enfraquecimento do poder da monarquia.

Em termos locais, cumpre-se ressaltar que tanto o presidente provincial - Antonio Alfredo da Gama e Melo - quanto o diretor da instrução pública - Ivo Magno Borges da Fonseca - do referido momento histórico, eram representantes legítimos do grupo liberal local. Nesse contexto, a instituição Escola Normal tornou-se objeto de disputa entre facções daqueles grupos. Mediante esta correlação de forças, no sentido gramsciano, ficou evidenciado que a implantação da escola normal estava condicionada aos interesses políticos que vinham movimentando aquela conjuntura.

Conforme registros jornalísticos ${ }^{7}$ disponibilizados, facções do grupo conservador não pouparam ataques e críticas as atitudes administrativas dos representantes das ideias de liberdades - o grupo liberal da Província na condição de situação. Na sua maioria, as denúncias e críticas recaíram sobre o descaso com a instrução pública, com a prática do nepotismo e com o desinteresse pelo cumprimento da ordem imperial com relação ao ato de instituir a Escola Normal na Parahyba do Norte por parte tanto do presidente provincial quanto do diretor da instrução pública de então.

Ao lado de outras questões e interesses políticos e apoiados naquele documento imperial, representantes do grupo conservador retomaram e reforçaram na sociedade política a ideia de instalar a Escola Normal anexa ao Liceu Paraibano. A justificativa para 
tal medida era economizar as finanças da província, uma vez que já existia uma estrutura física e um quadro pessoal que, além de capacitado, estava disponível para a concretização da Escola Normal. Assim, entende-se que esse movimento conjuntural de correlação de forças foi decisivo para o desmonte do Liceu Paraibano. Os trechos do Jornal da Parahyba do dia 29 de abril de 1882 confirmam as questões elucidadas.

$\mathrm{O}$ articulista ${ }^{8}$ parece que delira. E porque?

Porque temos concorrido para que a instrucção popular não continue a ser feudo do articulista e de seus intimos...

$[\ldots]$

Tractando da escola normal, muito de proposito não quizemos indicar o melhor meio de seu estabelecimento, com receio de que nossas opiniões não fossem aceitas pelo governo e pela illustre congregação do lyceu, deixando assim que o governo, d'accordo com a congregação, obrasse como the parecesse mais conveniente.

Entretanto, [...] entendemos que, pelo lado da economia, deve ella ficar annexa ao lyceu, refundindo-se este n'ella, sob a direção d'um conselho director, encarregado de decidir todas as questões a ella referentes, com a approvação do governo.

Para solucionar o impasse sobre onde e como instalar a Escola Normal da Parahyba do Norte, o diretor da Instrução Pública, Ivo Magno Borges da Fonseca, sobre pressão política, acatou a sugestão de formar uma comissão composta por professores do Liceu Paraibano. Esta comissão foi composta pelos seguintes docentes: Thomaz d'Aquino Mindello, Antonio Thomaz Carneiro da Cunha e Maximiano José Inojosa Varejão9 e tinha como tarefa apreciar a solicitação ministerial e emitir um parecer sobre a questão.

Após um levantamento sobre a situação da instrução pública, dos benefícios e importância da institucionalização da Escola Normal e das condições impostas pelo governo monárquico, entende-se que a referida comissão tentou equilibrar os interesses e as pressões dos grupos opositores. Antes de reproduzir o parecer, cumpre-se observar dois aspectos que chamou atenção. O primeiro refere-se à confirmação de que a criação daquela instituição foi resultante da correlação de forças que caracterizava o contexto de então. $\mathrm{O}$ outro está relacionado com o fato de que os membros daquela comissão referiram-se a instituição Escola Normal enquanto ensino normal. Assim, encerrou o seu parecer com as seguintes indicações ${ }^{10}$ :

1. ${ }^{\circ}$ - Que seja annexado ao Lyceu o ensino normal, segundo o plano proposto, sendo as respectivas materias que forem identicas as d'aquelle estabelecimento, distribuidas aos actuaes professores d'elle, os quaes poderão accumular, mediante rasoavel gratificação, o ensino de algumas outras para que tiverem as precisas habilitações, e criando-se novas cadeiras para o ensino que não poderem ser accumuladas, ou não convier que a sejam.

2. ${ }^{\circ}$ - Que além do pessoal docente, seja também aproveitado o da direcção, escripturação e policia da Instrucção Publica da Provincia, augmentando-se vencimentos á todos elles, como auxilio promettido pelo Governo, e marcando-se vencimentos para os professores das cadeiras, que forem criadas, assim como os novos empregados, que forem exigidos pelo acréscimo de serviço.

Entende a comissão que pode ser dispensado, por ora, o ensino d'alguma das matérias mencionadas no programma do Governo - Gymnastica, 
Pratica manual de officios, e principios de lavoura, e horticultura ${ }^{11}$. (Grifos nossos).

Essas circunstâncias possivelmente tenham impulsionado o gestor provincial, Jose Ayres do Nascimento a sancionar a Lei de $\mathrm{N}^{\circ}$. 761 no dia 7 de dezembro de 1883, determinando no parágrafo terceiro do seu artigo primeiro, a "Conversão do Liceu em escola normal de dois graus, ficando criada a cadeira de pedagogia, cujo professor terá as mesmas vantagens que os outros". (apud PINHEIRO; CURY, 2004, p. 57). Cabe recordar que tanto a proposta inicial originada no grupo conservador quanto a decisão da comissão apresentada no parecer acima, era a de instalar de forma anexa ao Liceu Paraibano a Escola Normal. Não obstante, a decisão oficial foi a de suprimir a primeira instituição a favor da segunda destinada a formar professores para as atividades instrucionais nas escolas públicas primárias paraibanas.

Em suma, a quarta tentativa de formar professores, ou seja, a Escola Normal oficialmente criada em função da supressão do Liceu Paraibano em 1883, foi instalada apenas em 1885. Nesse mesmo ano, através da Resolução 288 de 11 de novembro, o Liceu foi restaurado ganhando um novo Estatuto.

\section{Palavras (in)conclusivas}

As iniciativas ensaiadas, projetadas tais como: Classes normais (1861), Escola Normal (1864), Cadeira de ensino normal no Liceu Paraibano (1874) e a Conversão do Liceu Paraibano em Escola Normal (1883) aqui analisadas, de um lado sinalizaram um esforço do poder público em institucionalizar a formação de professores para o exercício no magistério especificamente nas escolas primárias. Por outro lado, representaram as oscilações dos gestores públicos e das lideranças políticas entre o discurso da necessidade e importância da formação de professores e a efetivação prática de uma instituição específica. $\mathrm{Na}$ verdade, considerando o cenário conflitante de época, entende-se que aquelas investidas revelam a contradição, o ponto de tensão entre o velho e o novo no âmbito educacional e social mais amplo no cotidiano da sociedade paraibana.

Apesar daquelas iniciativas não terem logrado êxito, sem perder de vista o ideário iluminista, principalmente os princípios de civilidade, progresso e de regeneração social, não houve o arrefecimento da necessidade e da possibilidade de institucionalizar a formação de professores através da Escola Normal da Parahyba do Norte, com vistas a melhoria da qualidade do ensino primário.

Uma outra questão que não pode ser desconsiderado nesse momento é que muito embora acanhadas e malogradas, as tentativas forneceram elementos fundamentais que concorreram para implantar um modelo escolarizado de formação de professores. Este modelo foi exatamente a Escola Normal denominada de Viveiro de Preceptores instalada oficial e majestosamente apenas em 1885. Esta instituição normatizadora da formação de professores se constitui em objeto do próximo estudo.

\section{Referências}

ALMEIDA, José Ricardo Pires. Instrução pública no Brasil (1500-1889): História e Legislação. 2. ed. Tradução Antonio Chizzotti. São Paulo: EDUC, 2000.

GRAMSCI, Antonio. Concepção dialética da história. Tradução de Carlos Nelson Coutinho. Rio de Janeiro: Civilização Brasileira, 1989. 
Os intelectuais e a organização da cultura. Tradução de Carlos Nelson Coutinho. Rio de Janeiro: Civilização Brasileira, 1988.

GURJÃO, Eliete de Queiroz. Morte e vida das oligarquias: Paraíba (1889-1945). João Pessoa: Editora Universitária/UFPB, 1994.

KULESZA, Wojciech A. A institucionalização da Escola Normal no Brasil (1870-1910). Revista Brasileira de Estudos Pedagógicos. V. 79, №. 193. Brasília: O Instituto, 2000, $63-$ 71.

LEWIN, Linda. Política e parentela na Paraíba. Tradução de André Villalobos. Rio de Janeiro: Record, 1993.

LOPES, Antônio de Pádua Carvalho. Um viveiro muito especial: Escola Normal e profissão docente no Piauí. In: ARAUJO, José Carlos Souza [et al.], (orgs.). As escolas normais no Brasil: do império à república. Campinas, SP: Alínea, 2008, p. 107-122.

MELO, José Octávio de Arruda. História da Paraíba: lutas e resistências. João Pessoa: A União/Sec, 1994.

MELLO, José Baptista de. Evolução do ensino na Paraíba. João Pessoa: Imprensa Oficial, 1956.

MONARCHA, Carlos. Escola Normal da Praça: o lado noturno das luzes. Campinas, São Paulo: Editora da Unicamp. 1999.

PINHEIRO, Antonio Carlos F.; CURY, Claudia Engler (Orgs.). Leis e Regulamentos da Instrução da Paraíba no Período Imperial. Brasília: INEP, 2004. Disponível em http://www.inep.gov.br/estatisticas/cdeb_2004/PB.pdf. Acesso em 09/04/2007.

SAVIANI, Dermeval. A pedagogia no Brasil: história e teoria. Campinas, SP: Autores Associados, 2008. (Coleção Memória da Educação).

THOMPSON, Edward Palmer. A miséria da teoria ou um planetário de erros: uma crítica ao pensamento de Althusser. Tradução Waltensir Dutra. Rio de Janeiro: Zahar Editores, 1981.

\section{RELATÓRIOS E MENSAGENS DOS PRESIDENTES E DIRETORES DA INSTRUÇÃO PÚBLICA NA PROVÍNCIA PARAIBANA}

PARAHYBA DO NORTE, Província da. Discurso com que o Prezidente - Bazilio Quaresma Torreão - da Província da Paraiba fez abertura da sessão ordinária da Assembléa Provincial no mez de janeiro de 1837. Cidade da Paraiba na Typographia Paraibana, 1837. Disponível em: http://www.crl.edu/content/brazil/pari.htm. Acesso em 06/04/2008.

Relatório da Instrucção Pública - Directoria da Instrucção Pública em 1 de março de 1861. [Diogo Velho Cavalcanti de Albuquerque] In: Relatorio com que o ill.mo e ex.mo snr. barão de Mamanguape recebeu do ill.mo e ex.mo snr. dr. Luiz Antonio de Silva Nunes, a administração da provincia da Parahyba do Norte a 17 de março de 1861. Parahyba, Typ. De José Rodrigues da Costa, 1861. Disponível em: http://www.crl.edu/content/brazil/pari.htm. Acesso em 18/04/2009.

Anexo G, Instrucção Pública, - Directoria da Instrucção Pública em 3 de abril de 1862. [Diogo Velho Cavalcanti de Albuquerque] In: Relatorio apresentado á Assembléa Legislativa Provincial da Parahyba do Norte, no dia 31 de maio de 1862, pelo presidente, 
dr. Francisco d'Araujo Lima. Parahyba, Typ. de José Rodrigues da Costa, 1862. Disponível em: http://www.crl.edu/content/brazil/pari.htm. Acesso em 18/04/2009.

Relatório da Instrucção Pública - Directoria da Instrucção Pública em 31 de agosto de 1864 [João Florentino Meira de Vasconcelos] In: Relatorio apresentado á Assembléa Legislativa Provincial da Parahyba do Norte no dia 1 de outubro de 1864 pelo presidente, dr. Sinval Odorico de Moura. Parahyba, Typ. de José Rodrigues da Costa, 1864. Disponível em: http://www.crl.edu/content/brazil/pari.htm. Acesso em 15/04/2008.

Anexo N. 8, Instrucção Pública, - Directoria da Instrucção Pública em 22 de junho de 1866. [Fructuoso da Soledade Segismundo] In: Relatorio apresentado á Assembléa Legislativa Provincial da Parahyba do Norte pelo 1.o vice-presidente, exm. sr. dr. Felisardo Toscano de Brito, em 3 de agosto de 1866. Parahyba, Typ. Liberal Parahybana, 1866. Disponível em: http://www.crl.edu/content/brazil/pari.htm. Acesso em 15/04/2008.

Relatorio apresentado a Assembléa Legislativa Provincial da Parahyba do Norte pelo 2.o vice-presidente, exm. sr. barão de Maraú em 5 de agosto de 1867. Parahyba, Typ. Liberal Parahybana, 1867. Disponível em: http://www.crl.edu/content/brazil/pari.htm. Acesso em 15/04/2008.

Anexo N. IV, Instrucção Pública, - Directoria da Instrucção Pública em 25 de Julho de 1871. [Joaquim Moreira lima] In: Falla dirigida á Assembléa Legislativa Provincial da Parahyba do Norte pelo exm. sr. 3.o vice-presidente da provincia, dr. José Evaristo da Cruz Gouvêa em 16 de outubro de 1871. Parahyba, Typ. Conservadora, 1871. Disponível em: http://www.crl.edu/content/brazil/pari.htm. Acesso em 17/04/2008.

Falla dirigida á Assembléa Legislativa Provincial da Parahyba do Norte pelo exm. sr. presidente da provincia, dr. Francisco Teixeira de Sá, em 6 de setembro de 1873. Parahyba, Typ. dos herdeiros de José R. da Costa, 1873. Disponível em: http://www.crl.edu/content/brazil/pari.htm. Acesso em 17/04/2008.

Relatorio apresentado á Assembléa Legislativa da provincia da Parahyba do Norte em 7 de agosto de 1874 pelo presidente, exm. sr. dr. Silvino Elvidio Carneiro da Cunha. Parahyba, Typ. do Jornal da Parahyba, 1874. Disponível em: http://www.crl.edu/content/brazil/pari.htm. Acesso em 17/04/2008.

. Relatorio apresentado a Assemblea Legislativa Provincial da Parahyba do Norte pelo presidente, exm. sr. dr. Manoel Ventura de Barros Leite Sampaio, em 4 de outubro de 1882. Parahyba, Typ. do Commercio, 1882. Disponível em: http://www.crl.edu/content/brazil/pari.htm. Acesso em 17/04/2008.

\section{LEGISLAÇÃO}

ACTOS DO PODER EXECUTIVO - Decreto N. 7247 - de 19 de abril de 1879. Disponível em http://www.histedbr.fae.unicamp.br. Acesso em 25/08/2009.

\section{ARTIGOS DE JORNAIS}

Editorial. Jornal da Parahyba. Anno XXI, N. 2225, Parahyba do Norte, 25 mar. 1882.

Editorial. Jornal da Parahyba. Anno XXI, No. 2226, Parahyba do Norte, 29 mar. 1882.

Editorial. Jornal da Parahyba. Anno XXI, Nº. 2228, Parahyba do Norte, 12 abr. 1882. 
Editorial. Jornal da Parahyba. Anno XXI, N. 2231, Parahyba do Norte, 29 abr. 1882.

Editorial. Jornal da Parahyba. Anno XXI, N. 2233, Parahyba do Norte, 10 mai. 1882.

Editorial. Jornal da Parahyba. Anno XXI, N. 2234, Parahyba do Norte, 13 mai. 1882.

Editorial. Jornal da Parahyba. Anno XXI, N. 2235, Parahyba do Norte, 24 mai. 1882.

Editorial. Jornal da Parahyba. Anno XXI, No. 2241, Parahyba do Norte, 21 jun. 1882.

\section{Notas}

${ }^{1}$ Universidade Federal da Paraíba - UFPB

2 Em contato com os organizadores da obra Leis e Regulamentos da Instrução da Paraíba no Período Imperial, a clientela prevista para ingressar na Escola Normal era apenas do sexo masculino. Portanto, houve um erro de digitação. No lugar de candidatas, lê-se candidatos.

${ }^{3}$ Monarcha (1999) e Saviani (2008) elaboraram considerações quanto aos aspectos moralizante e cultural que caracterizaram os programas de formação de professores nas escolas normais no período monárquico.

${ }^{4}$ Com relação às rendas da Província paraibana observa-se em alguns relatórios afirmações que revelam que os gastos com a educação escolar eram considerados supérfluos e, muitas das vezes inúteis. No geral, os gestores provinciais pregavam aos seus pares que aqueles gastos oneravam demais os cofres públicos, prejudicando outras prioridades relacionadas ao setor produtivo economicamente.

${ }^{5} \mathrm{O}$ art. $9^{\circ}$ da Reforma Leôncio de Carvalho, além estabelecer o programa curricular do curso (citado no capitulo dois deste), apresenta as diretrizes gerais que deveriam reger o funcionamento da Escola Normal.

${ }^{6}$ Documento publicado no do Jornal da Parahyba, no dia 25/03/1882. Localizado no Instituto Histórico e Geográfico Paraibano - IHGP.

${ }^{7}$ As matérias do Jornal da Parahyba, órgão ligado ao grupo conservador local, na seção intitulada: Jornal da Parahyba publicadas nos dias 25 de março, 12 e 29 de abril, 10, 13 e 24 de maio e 21 de junho de 1882, localizadas no Instituto Histórico e Geográfico Paraibano - IHGP, revelam explicitamente o interesse do grupo conservador em desestruturar o governo provincial de então, que era do partido de oposição - o liberal.

${ }^{8} \mathrm{O}$ "articulista" a que se referiu o autor da matéria foi o diretor da Instrução Pública, Ivo Magno Borges da Fonseca.

${ }^{9}$ Secção: Jornal da Parahyba, do Jornal da Parahyba, em 10 de maio de 1882. Localizado no Instituto Histórico e Geográfico Paraibano - IHGP.

${ }^{10}$ Conforme matéria publicada no Jornal da Parahyba no dia 24 de maio do mesmo ano, facções do grupo conservador sentiram-se vitoriosas pelo fato da comissão reconhecer que a Escola Normal deveria ser anexada ao Liceu, contudo não concordaram com nenhuma das medidas propostas pela mesma, a saber: a acumulação de cadeiras pelos docentes do Liceu; aos salários diferenciados para os professores novatos e a dispensa das disciplinas elencadas.

${ }^{11}$ Jornal da Parahyba do dia 10 de maio de 1882, localizado no Instituto Histórico e Geográfico Paraibano IHGP.

Recebido em novembro-2012

Aprovado em agosto-2013 